\title{
Effect of kinesio taping on explosive muscle power of gluteus maximus of male athletes
}

Karien Mostert-Wentzel, Johannes J Swart, Lieketseng J Masenyetse, Bafana H Sihlali, Renier Cilliers, Leanne Clarke, Janette Maritz, Eliz-mari Prinsloo, Lozanne Steenkamp

Department of Physiotherapy, University of Pretoria, Pretoria, South Africa

Karien Mostert-Wentzel, BSc (Physiotherapy), MPhysT, MBA

Bafana H Sihlali, BSc (Physiotherapy), MPhysT

Johannes J Swart, BPhysT

Renier Cilliers, BPhysT

Leanne Clarke, BPhysT

Janette Maritz, BPhysT

Eliz-mari Prinsloo, BPhysT

Lozanne Steenkamp, BPhysT

South African Medical Research Council

Lieketseng J Masenyetse, BComm, BSc (Actuarial and Financial Mathematics), MSc (Mathematical Statistics)

Corresponding author: Karien Mostert-Wentzel (karien.mostert@up.ac.za)

Objective. To determine the short-term effect of kinesio tape on the explosive gluteus maximus power of male athletes, comparing a recommended application pattern with a placebo.

Methods. Sixty healthy university male athletes participated in this double-blinded randomised controlled trial. Those athletes with musculoskeletal injury 6 weeks prior to screening, serious medical condition(s) in the previous 6 months, or metabolic conditions affecting joint integrity were not selected. A different investigator from the one who administered the intervention randomly allocated participants to groups. Allocation was concealed. Group A $(n=30)$ received a recommended Y-strip kinesio tape application and group $\mathrm{B}(n=30)$ a neutral placebo application. Height displacement during a counter-movement jump was measured with a reliable Vertec apparatus. Measurements were recorded at baseline, immediately after strapping and 30 minutes later. Participants and raters were blinded to group assignment. Descriptive statistics and analysis of variance for repeated measures were used to determine the effect of time and group on the measurements. Post hoc analysis was done using the Tukey's method.

Results. Time (before, immediately after and 30 minutes after taping) had a significant effect on the measurements. All the measurements after intervention (either immediately or 30 minutes after) had significant differences compared with baseline (95\% CI $[0.59,2.29]$ and $[1.50,3.2]$ respectively.)

Conclusion. The recommended application type of taping with kinesio tape was equally effective in significantly improving the explosive power of the gluteus maximus in male athletes immediately after and 30 minutes after taping in both groups.

S Afr J SM 2012;24(3):75-80. DOI:10.7196/SAJSM.261

\section{Introduction}

For an elite athlete a small improvement in athletic performance could mean the difference between a gold medal and a silver one. Sports activities that demand jumping, kicking, throwing and a sudden burst of power to change direction require explosive muscle power. ${ }^{1}$ Maximum explosive power is the capability of the neuromuscular system to create a single maximum voluntary contraction at maximum speed. ${ }^{2-4}$ It is possible that cutaneous application of athletic tape could improve muscle explosive power through increased sensory input to the neuromuscular system and increased activation of the sensorimotor reflex pathway. ${ }^{5}$

Athletic taping is therefore a modality with the potential to improve athletic performance that depends on explosive muscle power. Taping has been used to enhance proprioception, stability, function and muscle length in sites such as the ankle, ${ }^{6}$ knee, ${ }^{7,8}$ neck, ${ }^{9}$ shoulder girdle, ${ }^{10}$ upper limb ${ }^{11}$ and trunk. ${ }^{12}$ Although the use of kinesio tape is more widely recognised in rehabilitation, previous studies have also investigated the effect of the tape in uninjured subjects. ${ }^{5,6,13-18}$

A recently developed type of tape, kinesio tape, has been used in sports worldwide. Kinesio tape has advantageous mechanical characteristics compared with other types of taping, which lose their structural support within 20 minutes of exercise..$^{19}$ Kinesio tape is an elastic, latex-free tape which can be worn 24 hours a day for up to 4 days. This type of tape is approximately the same thickness as the epidermis, consists of $100 \%$ cotton (allowing for faster evaporation of sweat and drying time) and has acrylic, heat-activated glue. Another characteristic is the ability to stretch $130-140 \%$ of its original longitudinal static length. ${ }^{12}$ Kinesio tape is understood to improve muscle tone through the recruitment of muscle spindles via the sensorimotor pathway. ${ }^{20}$

With the sensorimotor mechanism the tape stimulates the mechano-receptors in the skin exteroceptors and, by reflex action, 
induces changes in muscle tone. ${ }^{15}$ Slupik et al. revealed increased recruitment of motor units in the vastus medialis oblique muscle, expressed as peak torque, up to 24 hours after applying kinesio tape to the vastus medialis oblique muscle of 27 healthy subjects with a mean age of 23 years. The bio-electrical activity of an isometric contraction was measured by transdermal electro-myography (EMG). The authors speculated that a reflex effect on the nervous system may have been responsible for the increase in peak torque. They proposed that a greater number of motor units are stimulated during a maximal contraction or that higher tone is generated by a single motor unit, or a combination of both of these factors.

Most vertical explosive activities involve a counter-movement during which the muscles are first stretched and then shortened to accelerate the body or limb. Power is more strongly associated with the ability to perform a vertical jump than force. ${ }^{21}$ The gluteus maximus muscle is the prime mover in the upper propulsion phase during a vertical jump. ${ }^{22,23}$ The agonistic function of the gluteus maximus muscle is hip extension and lateral rotation and produces $30 \%$ of the work (integral of force with respect to muscle tendon complex length) during a counter-movement jump (CMJ)..$^{23}$

It would appear that evidence for the efficacy of kinesio tape is lacking, ${ }^{24}$ as no randomised controlled trials could be found in the Medline (Ovid), Cinahl, Pedro and EbscoHost databases about the effects of kinesio tape on explosive muscle power. Therefore, the purpose of this study was to investigate the shortterm effect of applying kinesio tape on explosive muscle power of the gluteus maximus muscle. This effect was examined for both a recommended and a placebo method of application. The Y-strip kinesio tape application method (group A) is the method of taping recommended by the Kinesio Taping Association (KTA) and was compared to the I-method of taping (group B). The Y-method allows for large exposure to taping, stimulating a great number of cutaneous mechanoreceptors. ${ }^{12}$

We hypothesised that the Y-strip kinesio tape application method (group A) would cause a greater increase in explosive muscle power of gluteus maximus muscle from baseline to post-application in male athletes than the I-method application (group B) would.

\section{Methods \\ Subjects}

The study was conducted at the High Performance Centre at the LC de Villiers Sports Grounds, University of Pretoria, in May 2010. Sixtyeight healthy uninjured subjects who were training for competitive sporting events at university level (specifically the first team) were approached for participation in this study. The sample comprised 60 male athletes of different sporting codes between the ages of 18 and 28 training at the university. Fig. 1 depicts the flow of subjects.

Exclusion criteria were:

- musculoskeletal injury in the 6 weeks prior to the study

- medical condition(s) or pathology in the previous 6 months that could have caused a disability (e.g. a disc prolapse)

- metabolic conditions that may have affected joint integrity

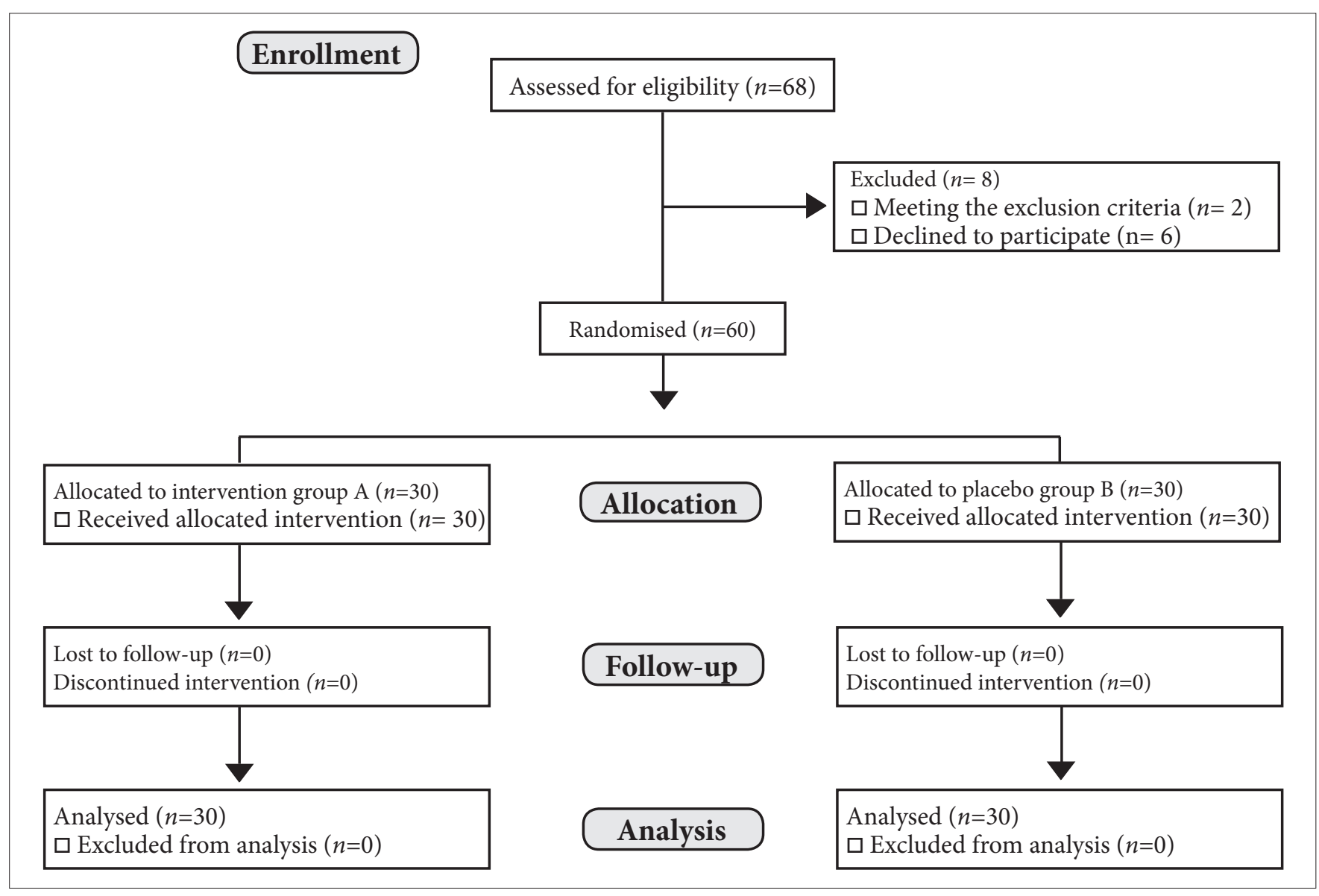

Fig. 1. Flow of subjects. 
- the use of illegal performance-enhancing medication or substances, e.g. anabolic steroids

- known adverse reactions to taping.

The study was approved by the Ethics Committee, Faculty of Health Sciences, University of Pretoria. Written informed consent was obtained from subjects before the intervention and their rights were protected.

\section{Sample size calculation}

A priori calculations indicated that a sample size of 30 subjects in each study group would give a power of $95 \%$ to detect a difference in the change in the height of the CMJ between the groups from baseline to immediately post taping and 30 minutes post taping at an alpha value of 0.05

\section{Randomisation}

Subjects were listed and numbered in the order in which they were enrolled. From this numbered list, they were allocated to either the Y-strip kinesio tape application group (group A) or to the placebo application group (group B). Allocation was done using computergenerated random numbers. A note with the letter of the allocated group, either an $\mathrm{A}$ or a B, was placed in a numbered opaque envelope. After he had consented to participate in the study, each subject received the numbered envelope that agreed with his name on the numbered list.

\section{Blinding}

The researcher responsible for the randomisation process also oversaw the training session and warm-up. The same researcher enrolled subjects. Another researcher, responsible for the strapping, opened the sealed envelope to identify which method of taping to apply on the subject. Subjects were not aware whether they were allocated to group A or to group B. They put on their exercise shorts directly after the taping to conceal the taping from those assessing the explosive muscle power.

\section{Material and apparatus}

Kinesio tape is available in different colours with no physical differences in physiological effect between tapes of different colours. Blue kinesio tape was used in this study.

The Vertec (Sports Imports Inc 2004) - the 'gold standard' for measuring vertical jumps - was used to measure the maximum jump height attained during a CMJ. ${ }^{26}$ The Vertec has plastic swivel vanes $1.13 \mathrm{~cm}$ apart and attached to an adjustable telescopic metal pole. The vertical jump height is the difference between the standing reach height and the highest displaced swivel vane. The apparatus is precalibrated when manufactured.

A Medalist (Model JS-7061) stopwatch was used to time the period between jumps ( 2 min apart) and for the 30-minute post-jump measurements.

\section{Intervention}

The researcher who applied the tape had completed the KT1 and KT2 Kinesio Taping course in June 2009 and was qualified to apply the tape in accordance with the Kinesio Taping Association guidelines.

Kinesio tape was pre-cut and then individually tailored to each subject just before application. Group A's taping was applied bilaterally over the gluteus maximus muscle, as illustrated in Figs 2 and 3. The two Y-shaped pieces of taping of approximately $35 \mathrm{~cm}$ long and $5 \mathrm{~cm}$

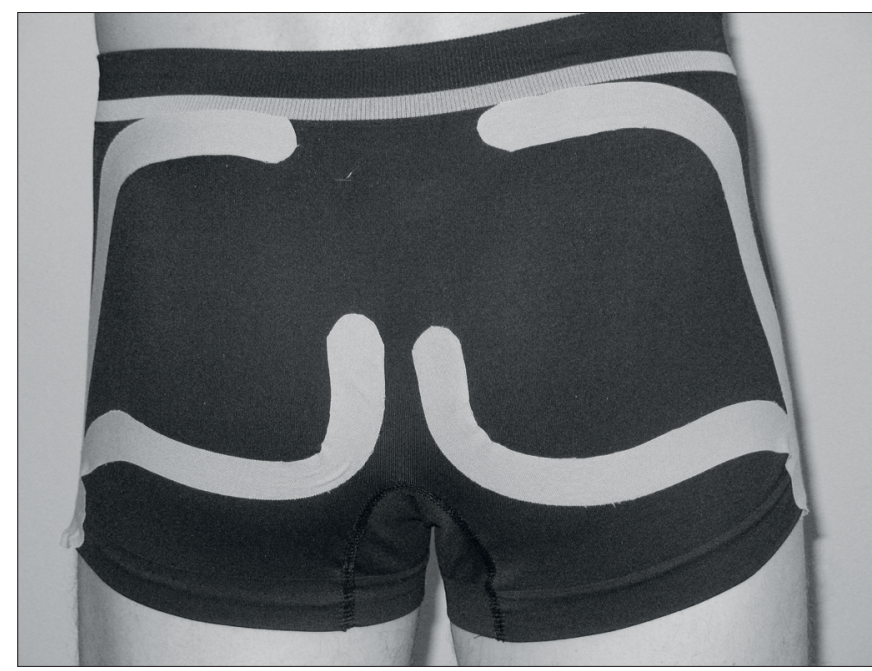

Fig. 2. Posterior view of the Y-strip KT application method (group A).

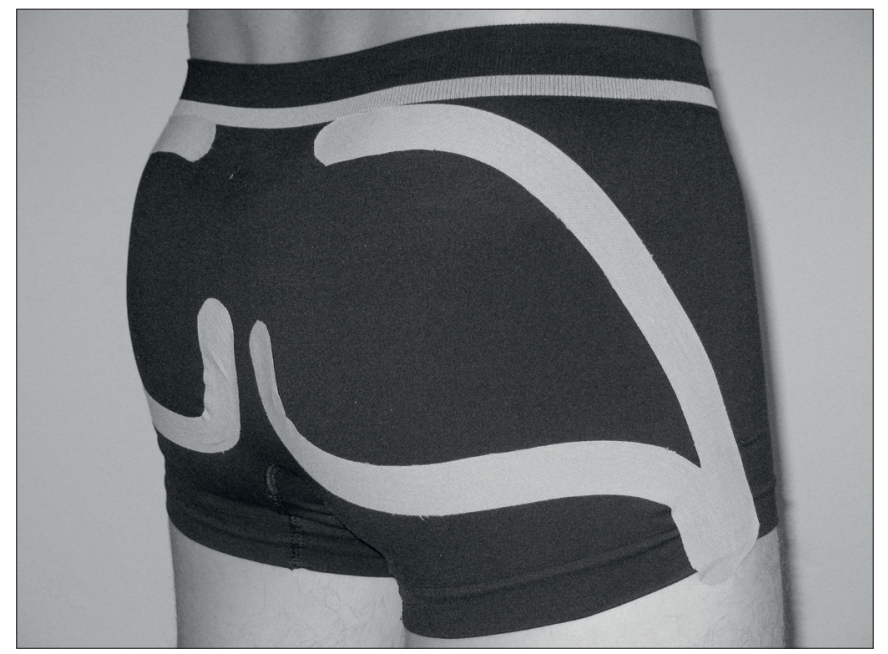

Fig. 3. Postero-lateral view of the Y-strip KT application method (group A).

wide were used. The tails of the $\mathrm{Y}$ were $30 \mathrm{~cm}$ long and $2.5 \mathrm{~cm}$ wide, leaving a base of $5 \mathrm{~cm}$ (the estimated distance between the subject's greater trochanter and fifth lumber (L5) spinous process). Subjects were asked to lie on their sides with the hip in neutral alignment. The base of the kinesio tape was stabilised and the anterior tail nearest to the clinician was taped to the iliac crest with tape tension of between $50 \%$ and $75 \%$. Subjects were then asked to flex, adduct and internally rotate the hip and flex the knee. The kinesio tape was stabilised and the posterior tail was attached to the sacral base, enclosing the gluteus maximus muscle, with the tape tension again between $75 \%$ and $100 \%$.

Group B's taping was applied in a neutral way without tension, based on other studies that used this method as a placebo (Figs 4 and 5). ${ }^{5,9}$ Two I-strips with a width of $2.5 \mathrm{~cm}$ and a length of $20 \mathrm{~cm}$ were applied horizontally to the middle of the gluteus maximus muscle. The strips were placed parallel to each other over the gluteus maximus muscle.

\section{The counter-movement jump (CMJ)}

The CMJ has high factorial validity and a reliability level with a Cronbach's $\alpha$ of 0.98 when tested on a contact-mat. ${ }^{27}$ The inter-class correlation coefficient ranges from 0.87 to 0.93 for male athletes using the highest jump of three jumps. ${ }^{28}$ 


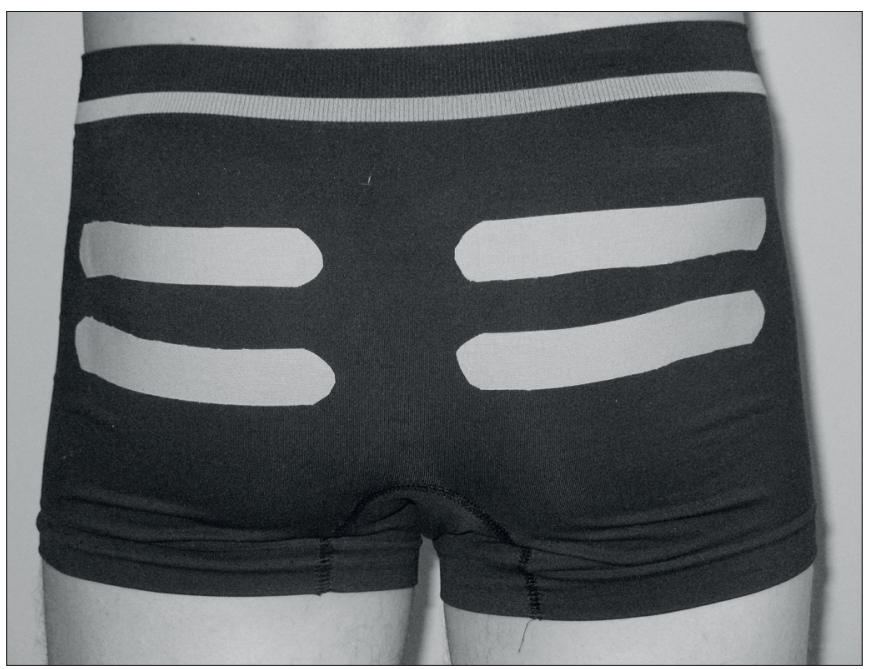

Fig. 4. Posterior view of the placebo I-strip placebo KT application method (group B).

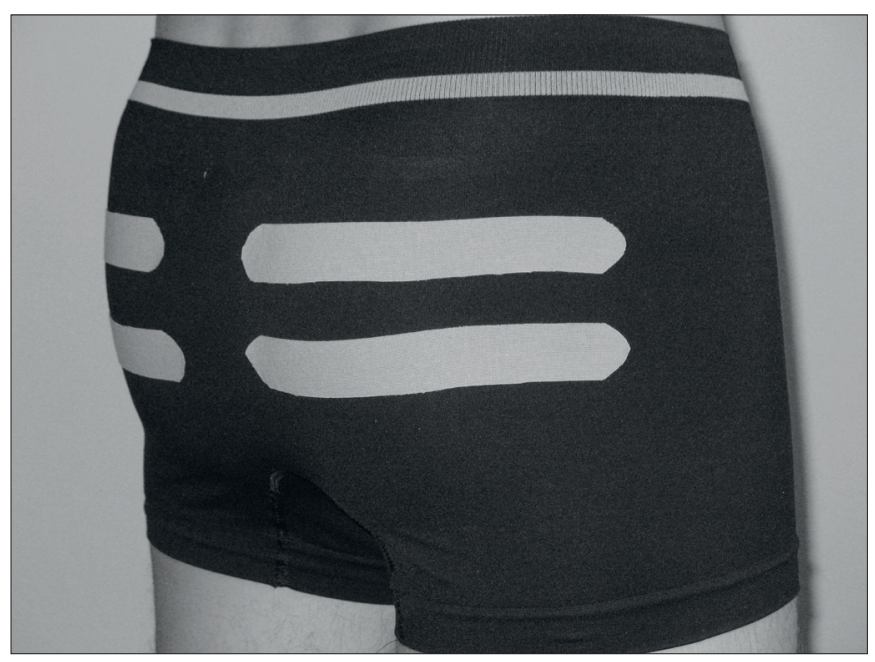

Fig. 5.Postero-lateral view of the neutral placebo KT application method (group B).

Subjects completed a standardised dynamic warm-up of 10 bodyweight squats, lunge walks for 10 metres and buttock kicks for 10 metres. Thereafter each subject performed $5 \mathrm{CMJs}$ at the Vertec at sub-maximal effort as training to decrease bias because of the learning effect. ${ }^{27}$ Five practice jumps have been shown to adequately reduce the effect of learning on improvement of the outcome measure. ${ }^{29}$

The CMJ was performed on a level non-slip concrete surface. Subjects were standing barefoot alongside the Vertec, under the vanes, with both hands reaching as high as possible while the heels remained on the floor. The Vertec was adjusted according to each subject's maximum reach and the measurements were documented. The subject then simultaneously swung his arms backwards and rapidly flexed his ankles, knees, hips and lower back in a continuous motion causing vertical propulsion when extended. In one flowing movement, at the maximum height of the vertical jump, the dominant hand was used to displace the vanes of the Vertec. A subject was asked to repeat the jump if preliminary steps were taken, if he shuffled his feet, or if a change in depth occurred during the jump.

\section{Procedure}

Subjects were booked for 1 of 6 sessions on either of the 2 allocated testing dates ( 1 and 8 May 2010). Groups of 5 subjects were assigned for each testing session with duration of 1.5 hours. Following the information and familiarisation session, written informed consent was obtained from each subject. Subjects completed the warmup session and the standing reach height was recorded. Baseline measurements that consisted of $3 \mathrm{CMJ}$ at maximal effort, 2 minutes apart, were recorded for each subject.

Thereafter subjects were strapped according to their allocated group. Immediately post taping, 3 CMJs were performed and recorded and were followed by a 30 -minute rest period. The warm-up was repeated prior to the last $3 \mathrm{CMJs}$ performed 30 minutes post taping. No subjects reported adverse effects of the taping.

\section{Data analysis}

Descriptive statistics consisting of means and standard deviations for the measurements were calculated. Analysis of variance (ANOVA) for repeated measures was used to determine the effect of time and group on the measurements. Post hoc analysis was done on significant variables $(p<0.05)$ after performing ANOVA using the Tukey's method. Analyses were done in STATA Version 12.

\section{Results}

The 60 male participants were equally divided between group $\mathrm{A}$ and group B. They participated in 15 sporting codes shown in Table 1 . The most prevalent codes were rugby, athletics and cricket. The 'other' category included one each of dancing, cycling, netball, long jump, high jump, triple jump, tennis, rock climbing and squash.

\begin{tabular}{ll} 
Table $\mathbf{1}$. Frequency by sporting code & $(\mathbf{N}=\mathbf{6 0})$ \\
\hline Sporting code & Frequency \\
\hline Rugby & 21 \\
Athletics & 17 \\
Cricket & 16 \\
Hockey & 4 \\
Gymnastics & 3 \\
Golf & 2 \\
Other & 9 \\
'Participants could provide more than one code. &
\end{tabular}

The baseline mean was $68.26 \mathrm{~cm}$ for group A, while it was $66.61 \mathrm{~cm}$ for group B (Table 2). In both groups the measurements increased over time (from baseline to directly post taping to 30 minutes post taping). The ANOVA showed that there was no significant mean difference between the measurements for the two groups $(p=0.21)$. Time (before, immediately after and 30 minutes after taping) had a significant effect on the measurements $(p<0.001)$. However, no significant difference $(p=0.52)$ in the way the groups changed over time was found.

Given the significant effect of time, post hoc analysis was performed to determine the means that were different (Table 3.) All the measurements after intervention (either immediately or 30 minutes after) had significant differences compared with baseline. In addition to that, measurements immediately after intervention 
Table 2. Counter-movement jump heights at different points in time by group $(N=60)$

\begin{tabular}{lccc}
\hline & \multicolumn{3}{c}{$\begin{array}{c}\text { Mean } \pm \text { SD }(\mathrm{cm}) \\
\text { Time point of the measurement }\end{array}$} \\
\cline { 2 - 4 } & Baseline & Immediately post intervention & 30 min post intervention \\
\hline Group A $(\boldsymbol{n}=\mathbf{3 0})$ & $68.26 \pm 6.10$ & $70.00 \pm 6.05$ & $71.10 \pm 5.24$ \\
Group B $(\boldsymbol{n}=\mathbf{3 0})$ & $66.61 \pm 7.17$ & $67.76 \pm 7.90$ & $68.47 \pm 8.36$
\end{tabular}

Table 3. Pairwise comparisons by time $(N=60)$

\begin{tabular}{lcc}
\hline Time points & Mean difference between time points $(\mathbf{c m})$ & 95\% Confidence Interval \\
\hline Immediately after intervention - baseline & $1.44^{*}$ & {$[0.59,2.29]$} \\
30 min after intervention - baseline & $2.35^{*}$ & {$[1.5,3.2]$} \\
30 min after intervention - immediately after intervention & $0.91^{*}$ & {$[0.06,1.76]$} \\
*Significantly different. & &
\end{tabular}

and 30 minutes after intervention had a significant difference [mean difference between time points $=0.91,95 \%$ CI $[0.06,1.76)]$.

\section{Discussion}

To the best of the authors' knowledge, this study was the first to assess the effect of kinesio tape on explosive muscle power in healthy male athletes. The main finding was that kinesio tape improves short-term muscle power of the gluteus maximus directly after application and 30 minutes later for both the groups. Although the improvements in jump height may appear small $(95 \%$ CI $[1.5 ; 3.2])$, even differences of this magnitude can influence medal placings at a high-performance level. For example, both the silver and bronze medalists for the high jump at the 2012 Olympic Games reached a maximum jump height of $2.03 \mathrm{~m}$. This fact would suggest that the application of kinesio tape may provide a meaningful improvement in performance in certain sports.

The main effect of kinesio tape is attributed to applying the tape with tension, as was done for the Y-application method (group A). ${ }^{13}$ This provides a pulling force, which causes a change in stretch load, pressure and shear force, triggering the mechanoreceptors in the subdermal soft tissue and fascia. The central nervous system integrates the sensory input, and modulates gamma-motor firing, which in turn leads to increased muscle tone.

However, in this study the Y-strip application (group A) did not produce better results than the I-strip application without tension (group B). To explain this outcome, the researchers speculated that the group B application activates central mechanoreceptors on the larger surface area of the gluteus maximus muscle, and the group A application similarly stimulates mechanoreceptors along the boundaries of the muscle. Slupik et al. ${ }^{15}$ are also of the opinion that even without stretching, strapping has a facilitating effect on cutaneous mechanoreceptors with subsequent reflex motor stimulation.

One limitation of the study is that in the absence of a true control group with no taping, it is unclear whether the improvement in explosive power reflects a learning effect or equivalent efficacy for both taping methods. This limitation could also be addressed using a cross-over design where the same subjects performed randomised no-tape, Y-tape and placebo-tape jumps. A further consideration is that larger performance-enhancement effects might have been demonstrated in less trained individuals who may have been more likely to benefit from neuromuscular facilitation.

Although outcome of the study may have been affected by the outdoor testing environment, the testing took place in a square with walls on all sides that shielded the area from the wind. The maximum temperature reported according to the South African Weather Service for the first testing day was $18^{\circ} \mathrm{C}$ in the Pretoria area and $26^{\circ} \mathrm{C}$ on the second testing day. Rain that lasted for 30 minutes during the first testing day may have led to a decrease in the expected height difference in the post-taping measurements.

A limitation in the strapping technique was that body lotion had not been removed from patients' gluteal area and the area had not been shaved, which may have limited the adhesion of tape to the skin and resulted in less than optimal facilitation of cutaneous mechanoreceptors. On the other hand, pull on hair may have increased the stimulation via the mechanoreceptors in the hair follicles.

\section{Conclusion}

It would appear that kinesio tape applied to the gluteus maximus muscle of healthy young male athletes significantly increases shortterm vertical jump height as a proxy for explosive muscle power over time in both methods of application tested in this study. The hypothesis that the Y-strip kinesio tape application method (group A) would cause a greater increase in explosive muscle than the I-method application (group B) was therefore rejected.

The implication of the findings is that athletes participating in the high jump may benefit from strapping using either application within half an hour of jumping.

These findings need to be confirmed in a study that includes a notaping group so as to control for the influence of a learning effect. The effect of kinesio taping also needs to be tested after injury, as the use of kinesio tape, in addition to other modalities, may be effective in rehabilitating explosive power of the gluteus maximus muscle in male athletes. Future studies that monitor the long-term effects in a multi-staged way are also recommended. 
Acknowledgements. The authors wish to thank Lindsey Parry, Head Sport Scientist at the Institute for Sport Research High Performance Centre, University of Pretoria, for guidance and the use of apparatus and facilities; Phillip Labuschagne for initial assistance with statistical analysis; Hitech Therapy for sponsoring the Kinesio Tex Tape used in the study, Barbara English for language editing, and the participants.

\section{REFERENCES}

1. Newton RU, Kraemer WJ. Developing explosive muscular power: implication for a mixed methods training strategy. J Strength Cond Res 1994;Oct:20-31.

2. Thomas M, Fiatarone MA, Fielding RA. Leg power in young women: relationship to body composition, strength and function. Med Sci Sports Exerc 1996;29(10):13211326

3. Bahr R. Principles of injury prevention. In: Brukner P, Khan K, eds. Clinical Sports Medicine, $3^{\text {rd }}$ ed. Australia: McGraw-Hill, 2006:96.

4. Brukner P, Khan K, eds. Clinical Sports Medicine, $3^{\text {rd }}$ ed. Australia: McGraw-Hill, 2006:96.

5. Kilbreath SL, Perkins S, Crosbie J, McConnell J. Gluteal taping improves hip extension during stance phase of walking following stroke. Aust J Physiother 2006;52(1):53-56. [http://dx.doi.org/10.1016/S0004-9514(06)70062-9]

6. Murray HY, Husk LJ. Effect of kinesio taping on proprioception in the ankle. J Orthop Sports Phys Ther 2001;31:37.

7. Callaghan MJ, Selfe J, McHenry A, Oldham JA. The effects of patellar taping on knee joint proprioception in patients with patellofemoral pain syndrome. Man Ther 13(2008):192-199.[http://dx.doi.org/10.1016/j.math.2006.11.004]

8. Warden SJ, Hinman RS, Watson MA, Avin KG, Bialocerkowski AE, Crossley KM. Patellar taping and bracing for the treatment of chronic knee pain: a systematic review and meta-analysis. Arthritis Rheum Jan 2008;59(1):73-83. [http://dx.doi.org/ $10.1002 /$ art.23242]

9. González-Iglesias J, Gutiérrez-Vega M de R, Fernández-de-las-Peñas C, Cleland J. Short-term effects of cervical kinesio taping on pain and cervical range of motion in patients with acute whiplash injury: a randomized clinical trial. J Orthop Sports PhysTher 2009;39(7):515-521. [http://dx.doi.org/10.2519/jospt.2009.3072]

10. Thelen MD, Dauber JA, Stoneman PD. The clinical efficacy of kinesio tape for shoulder pain: a randomized, double-blinded, clinical trial. J Orthop Sports Phys Ther 2008;38(7):389-395. [http://dx.doi.org/10.2519/jospt.2008.2791]

11. Yasukawa A, Patel P, Sisung C. Pilot study: investigating the effects of kinesio taping in an acute pediatric setting. Am J Occup Ther 2006;60(1):104-110. [http://dx.doi. org/10.5014/ajot.60.1.104]

12. Yoshida A, Kahanov L. The effect of kinesio taping on lower trunk range of motions. Res Sports Med 2006;15:103-112. [http://dx.doi.org/10.1080/15438620701405206]

13. Chang HY, Chou KY, Lin J, Lin C, Wang C. Immediate effect of forearm kinesio taping on maximal grip strength and force sense in healthy collegiate athletes. Phys Ther Sport 2010;11(4):122-127. [http://dx.doi.org/10.1016/ j.ptsp.2010.06.007]

14. Fu TC, Wong AM, Pei YC, Wu KP, Chou SW, Lin YC. Effect of Kinesio taping on muscle strength in athletes: a pilot study. J Sci Med Sport 2007;11:198-201. [http:// dx.doi.org/10.1016/j.jsams.2007.02.011]

15. Slupik A, Dwornik M, Bialoszewski D, Zych E. Effect of kinesio taping on the bioelectrical activity of vastus medialis muscle. J Orthop Trauma Rehab 2007;6(9):644651.

16. Halseth T, McChesney JW, DeBeliso M, Vaughn R, Lien L. The effects of kinesio taping on proprioception at the ankle. J Sport Sci Med 2004;3:1-7.

17. Ackermann B, Adams R, Marshall E. The effect of scapula taping on electromyographic activity and musical performance in professional violinists. Aust J Physiother 2002;48:197-203

18. Cools A, Witvrouw E, Danneels LY, Cambier D. Does taping influence electromyographic muscle activity in the scapular rotators in healthy shoulders? Man The, 2002;7(3):154- 162. [http://dx.doi.org/10.1054/math.2002.0464]

19. Bragg RW, Macmahon JM, Overom EK, Yerby SA, Matheson GO, Carter DR Andriacchi TP. Failure and fatigue characteristics of adhesive athletic tape. Med Sci Sports Exerc 2002;34(3):403-410. [http://dx.doi.org/10.1097/00005768-20020300000004]

20. Macgregor K, Gerlach S, Mellor R. Cutaneous stimulation from patella tape causes a differential increase in vasti muscle activity in people with patellafemoral pain. J Orthop Res 2005;23:351-358. [http://dx.doi.org/10.1016/j.orthres.2004.07.006]

21. Davis DS, Briscoe DA, Craig T, Savilled SE, Taylor CJ. Physical characteristics that predict vertical jump performance in recreational male athletes. Phys Ther Sport 2003;4:167-174. [http://dx.doi.org/10.1016/S1466-853X(03)00037-3]

22. Spägele T, Kistner A, Gollhofer A. Modelling simulation and optimisation of human vertical jump. J Biomech 1999;32:521-530. [http://dx.doi.org/10.1016/S0021 9290(98)00145-6]

23. Bobbert MF, Casius LJR. Is the effect of a countermovement on jump height due to active state development? Med Sci Sports Exerc2005;37(3):441-446. [http://dx.doi. org/ 0.1249/ 01.MSS.0000155389.34538.97]

24. Hsu YH, Chen WY, Lin HC, Wang WTJ, Shih Y. The effects of taping on scapular kinematics and muscle performance in baseball players with shoulder impingement syndrome. J Electromyogr Kinesiol 2009;19(6):1092-1099. [http://dx.doi.org/10.1016/ j.jelekin.2008.11.003]

25. Sporis G, Milanovic L, Jukic I, Molinuevo JS. The effect of agility training on athletic power performance. Kinesiology 2010;42(1):65-72. udc:796.015.367-055.1 (497.5).

26. Caruso JF, Daily JS, McLagan JR, et al. Data reliability from an instrumented vertical jump platform. J Strength Cond Res 2010;24(10):2799-2808.[http://dx.doi. org/10.1519/ JSC.0b013e3181b66679]

27. Markovic G, Dizdar D, Jukic I, Cardinale M. Reliability and factorial validity of squat and countermovement jump tests. J Strength Cond Res 2004;18(3):551-555. [http:// dx.doi.org/10.1519/00124278-200408000-00028]

28. Moir G, Shastri P, Cannaboy C. Intersession reliability of vertical jump height in women and men. J Strength Condit Res 2008;22(6):1779-1784. [http://dx.doi. org/10.1519/ JSC.0b013e318185fodf]

29. Bradley PS, Olsen PD, Portas MD. The effect of static, ballistic and proprioceptive neuromuscular facilitation stretching on vertical jump performance. J Strength Condit Res 2007;21(1):223-226 200. [http://dx.doi.org/10.1519/00124278-200702000-00040] 